\title{
The Impact of a Lasting Economic Crisis on Employee Attitudes: A Follow-up and Extension
}

\author{
By Yannis Markovits* \\ Diana Boer ${ }^{+}$ \\ Sibylle Gerbers ${ }^{*}$ \\ Rolf van Dick ${ }^{+}$
}

This paper presents a follow-up study of Markovits et al. 's (2014) comparison of large samples of Greek employees before and at the onset of the economic crisis. Now at the crisis' peak, we again sampled data from 450 employees about their job satisfaction, organizational commitment, regulatory focus, and burnout. Overall, compared to the two samples before, employees' job attitudes further decrease with lower normative and higher continuance commitment, lower (extrinsic and intrinsic) job satisfaction and both lower promotion and (somewhat surprisingly) even lower prevention orientation. Expanding previous studies, results show that satisfaction and commitment are also related to burnout and that those participants who are currently employed but had experienced personal unemployment during the crisis showed more negative attitudes and higher burnout.

Keywords: Job satisfaction, organizational commitment, burnout, economic crisis, Greece, follow-up study

\section{Introduction}

For over half a decade now, the Greek economy is in a severe crisis. The present paper presents a follow-up and extension of a study by Markovits, Boer and van Dick (2014) who had examined the impact of this crisis on employees' job-related attitudes. Markovits et al. compared a sample of Greek employees surveyed at the onset of the economic crisis (in 2010/2011) with a sample of employees surveyed before the crisis (2004-2007) and found reduced job satisfaction and organizational commitment. Moreover, they have shown that the effects were mediated by changes in employees' regulatory focus (Higgins 1997). This means that the crisis shifted people's orientation from a promotion focus (i.e., a focus on gains and accomplishments; Higgins 1997) towards a prevention focus (i.e., a focus on risk avoidance; Higgins 1997) and that this contributed to lower satisfaction and commitment.

Greece still faces a severe debt crisis and is obliged to implement strict fiscal, monetary and structural reforms and restrictions, in order to receive

\footnotetext{
${ }^{*}$ Full-time employee, Ministry of Finance, Thessaloniki, Greece.

${ }^{\dagger}$ Full Professor of Social and Organizational Psychology, University of Koblenz-Landau, Koblenz, Germany.

* Student (MSc) of Psychology, Goethe University, Frankfurt, Germany.

${ }^{+}$Full Professor of Social Psychology, Goethe University, Frankfurt, Germany and Work Research Institute (AFI), Oslo, Norway..
} 
loans from the European Commission (EC), the International Monetary Fund (IMF), the European Central Bank (ECB), and the European Stability Mechanism (ESM). Over the past six years, Greece has signed three "Memorandum" programs which asked for the implementation of strict regulations. Greek politics and economy are now monitored and assessed by a "quartet" of international institutions (compared to the former "troika") and the government, led by the left-wing Syriza party, has signed the new treaty. The new government has managed to win three consecutive elections in January, July, and September 2015, respectively and signed the latest memorandum despite its promises to stop the programs and the monitoring.

As mentioned above, Markovits et al. (2014) compared the data of employees before and during the crisis. Employees were from the private sector in the geographical region of Thessaloniki, in the Northern part of Greece. This area is the second largest in Greece in terms of population and economy, and it is the region which has been hit the worst by the economic crisis. Markovits et al. showed that the crisis with its high unemployment rates and the poor employment prospects negatively impacted employees' extrinsic satisfaction, but not their intrinsic satisfaction. Employee affective (i.e. employees are committed because they want to) and normative commitment (i.e. employees are committed because they feel that they ought to) were significantly lower during the economic crisis compared to the pre-crisis sample, whereas continuance commitment (i.e. employees are committed because they need to) remained stable.

This study sets out to explore the situation about half a decade after the onset of the crisis and to answer the question whether employees have restored their job attitudes and commitment or are whether they would still suffer from the crisis.

The present paper has several aims. First, we examine the continued effects of the crisis on employee attitudes. To do this, we have conducted a "third" wave of the survey and again asked employees about their commitment and satisfaction. But we also aimed at extending the previous research. Therefore and secondly, we address the question whether the ongoing crisis also relates negatively to employee well-being, namely burnout. Finally, we test for differences between employees who have been personally affected by the crisis by experiences of unemployment and those who were less affected by the crisis personally.

Xanthopoulou and Epitropaki (2015) vividly state that the "Greek debt crisis (or Greek Depression) has been a cataclysmic unprecedented event... very few European countries have ever experienced unemployment rates of $27.9 \%$ or youth unemployment of $60.8 \%$... Approximately $47 \%$ of private sector companies report that they had to lay off people (from 5\% up to $40 \%$ of their workforce), $45 \%$ cut salaries (with cut rates between $6 \%$ and $40 \%$ ), $50 \%$ reduced bonuses, and $37 \%$ cut their training budgets" (p. 3 ).

The crisis hence continues to negatively affect employees and their families, which is likely to impact on job attitudes and well-being. 


\section{Attitudes over Time}

First, we test whether the ongoing crisis has further negative effects on employee attitudes or whether attitudes remain stable or recover after some time. Attitudes are not stable and can change due to social influences of the external environment such as economic and social developments (Eagly and Chaiken 1995, McGuire et al. 1985). An extreme form of such development is an economic crisis that affects the whole population. Greece is facing such a crisis and since 2010 one austerity program follows another, and thus, we could expect a further negative development of job attitudes. Attitudes may also change as a response to events that tap into people's emotions. Emotions are open to influence due to political changes, advertising, media campaigns and messages, and affective forecasting (Loewenstein 2007). This is important and is related to the present research, since the Greek population does not only experience a prolonged crisis, but also mixed expectations that something new is coming and things may change for the better.

So, although one might think that job attitudes may have recovered due to the recent promises of the Greek government and the fact that people adapt to their environments even under harshest conditions and restore their happiness rather adaptively (e.g., Diener and Diener 1996), we expect that the prolonged crisis has stabilized the low attitudes on the level of the crisis data, i.e., we expect that job satisfaction and organizational commitment are still lower than before the crisis but not higher than during the crisis (Hypothesis 1). We again focus on various forms of work-related satisfaction (i.e. job, extrinsic, intrinsic, pay, and job security), three facets of commitment (i.e. affective, normative and continuance) and the two regulatory foci (i.e. promotion und prevention).

\section{Job Attitudes and Burnout}

Relations between employee attitudes and burnout have been studied extensively during the last three decades. Job satisfaction has been shown to be negatively related to burnout in general and its dimensions emotional exhaustion and depersonalization in particular (e.g., Acker 1999, Evans et al. 2006, Martin and Schinke 1998, Onyett et al. 1997, Penn et al. 1988, Rosales et al. 2013). Most studies have been conducted in the health sector and the participants were mainly teachers, social workers and nurses which are professions involving high levels of stress. Tsigilis et al. (2006) conducted a study among primary school teachers in Greece and found that job satisfaction related to early educators' burnout and varied as a function of their workplace, i.e., satisfaction with the tasks and working conditions reduced emotional exhaustion. Leiter and Maslach (1988) found that burnout was negatively related to organizational commitment and King and Sethi (1997) found that employees with high levels of affective commitment had lower burnout and that commitment acted as a buffer against stress. Similar negative relationships were shown in numerous studies since, most of them focusing on the health and education sectors (see the meta-analysis by Meyer et al. 2002). 
Thus, we predict that Greek employees who report lower job satisfaction and organizational commitment also report higher burnout, i.e., more depersonalization and emotional exhaustion (Hypothesis 2). Whereas our first hypothesis will be tested across the three survey waves, the second hypothesis will be tested in the "third wave" only as burnout has not been part of the study design before.

\section{Job Attitudes and Unemployment}

Attitudes are influenced by and are most predictive of individual's behaviors when they have a high degree of personal relevance. To explore whether this is the case in the current context, we included questions about personal experience with unemployment. Extensive research has shown the detrimental effects of unemployment on mental health (Dooley et al. 1996, Murphy and Athanasou 1999, Paul and Moser 2006). We extend these findings by looking at detrimental effects of recently experienced unemployment on job satisfaction and commitment at times of a severe crisis. We predict that employees who have been unemployed themselves during the crisis will report lower satisfaction and commitment and higher burnout than those who have not had experienced unemployment personally (Hypothesis 3).

\section{Methods}

\section{Participants}

Overall, 454 employees completed the survey. Age was measured in three categories and distributed as follows: $15 \%$ were between 20 and 34 years, $36.4 \%$ between 35 and 45 years and $48.6 \%$ over 46 years old. $53.2 \%$ of the sample was female; $11.8 \%$ had working experience of up to 6 years, $21.6 \%$ between 7 and 12 years, $34.1 \%$ between 13 and 21 years and $32.5 \%$ more than 22 years. Education was distributed as follows: $23.4 \%$ higher education, $33.6 \%$ further education and $43 \%$ had a postgraduate degree. $64 \%$ of the sample was married and $68 \%$ had at least one child.

The sample showed a similar gender balance as in the 2004 and 2011 samples (pre-crisis: $51.2 \%$ female, Chi-square $(1)=0.71, p>.05$; beginning crisis: $50.5 \%$ female, Chi-square $(1)=1.03, p>.05)$, but participants were somewhat older in the present sample (comparison with pre-crisis: Chi-square $(2)=65.88, p<.001$; beginning crisis: Chi-square $(2)=140.10, p<.001)$.

We controlled for age and gender in the analyses (but did not find any significant differences between the analyses not controlling for the demographics). About $12 \%$ of participants have had experiences with unemployment $(n=53)$

\section{Procedure and Questionnaire}

The current study was conducted in the same geographical region as the two previous surveys. This time, participants responded to an online survey created by the third author and hosted on the platform www.unipark.de. 
The questionnaire comprised four parts. First, we used exactly the same items to measure job satisfaction (extrinsic and intrinsic), commitment (affective, normative, and continuance) and regulatory focus (promotion and prevention orientation) as in the previous surveys. The items are based, respectively, on the Minnesota Satisfaction Questionnaire - MSQ (Weiss et al. 1967), the commitment scales developed by Allen and Meyer (1990), and a scale on promotion and prevention focus by Lockwood et al. (2002). All items had been translated by the first author into Greek and had shown good psychometric properties in the previous surveys by Markovits et al. (2007, 2008, 2010, 2014).

Secondly, burnout was measured by the classic instrument developed by Maslach and Jackson (1981). To keep the questionnaire within acceptable limits we decided to use two aspects of burnout, i.e., depersonalization and emotional exhaustion. Items were translated by the first author.

All scales and sub-scales reveal high reliability coefficients (alpha Cronbach's) except for continuance commitment $(\alpha=.57)$ and prevention focus $(\alpha=.50)$ - as both are standard instruments which have been used extensively before, we decided to proceed with the analyses.

\section{Results}

Table 1 presents an overview of the data of this follow up study. The jobrelated attitudes present significant inter-correlations (apart from continuance commitment) and they are correlated to promotion focus, but not significantly with prevention focus. Both burnout scales (depersonalization and emotional exhaustion) are significantly correlated with attitudes and regulatory foci - the more satisfaction, commitment and promotion, the lower is burnout on both dimensions and vice versa for prevention focus.

To test Hypothesis 1, we compared job satisfaction, organizational commitment and regulatory foci between the three "waves" (the "pre-crisis" sample, the "beginning crisis" sample, and the "high crisis" sample), by conducting ANOVAs with subsequent post-hoc tests. We tested for age and gender to account for slight imbalances between the samples regarding these characteristics (results without controls were almost identical). Results are presented in Figure 1 and Table 2, which show significant differences for all tested differences.

Post-hoc tests show interesting trends: Job satisfaction and all its facets and also normative commitment are significantly lower compared to both the pre-crisis and the beginning-crisis data. Affective commitment and job security have remained low but stable compared to 2010 and continuance commitment increased considerably. Prevention focus decreased whereas promotion focus remains on the low level from 2010. 
Table 1. Means, Standard Deviations, Cronbach's Alphas (in italics in the diagonal) and Correlation Coefficients for all Study Variables of the Follow up Survey

\begin{tabular}{|c|c|c|c|c|c|c|c|c|c|c|c|c|c|c|}
\hline & M & SD & 1 & 2 & 3 & 4 & 5 & 6 & 7 & 8 & 9 & 10 & 11 & 12 \\
\hline 1. Job satisfaction & 50.95 & 19.79 & .94 & & & & & & & & & & & \\
\hline 2. Extrinsic satisfaction & 49.45 & 19.83 & $.93 * *$ & .87 & & & & & & & & & & \\
\hline 3. Intrinsic satisfaction & 53.92 & 22.25 & $.94 * *$ & $.76^{* *}$ & .92 & & & & & & & & & \\
\hline 4. Pay satisfaction & 42.00 & 27.39 & $.58 * *$ & $.66^{* *}$ & $.43 * *$ & .85 & & & & & & & & \\
\hline 5. Job security & 58.35 & 26.89 & $.66^{* *}$ & $.72 * *$ & $.55 * *$ & $.41 * *$ & .80 & & & & & & & \\
\hline 6. Affective commitment & 54.80 & 23.77 & $.63 * *$ & $.56^{* *}$ & $.62 * *$ & $.33 * *$ & $.40 * *$ & .84 & & & & & & \\
\hline 7. Continuance commitment & 61.01 & 17.27 & $.10^{*}$ & .08 & $.10^{*}$ & .06 & .04 & $.11 *$ & .57 & & & & & \\
\hline 8. Normative commitment & 43.81 & 22.80 & $.58 * *$ & $.54 * *$ & $.55 * *$ & $.36 * *$ & $.35^{* *}$ & $.75 * *$ & $.26^{*}$ & .81 & & & & \\
\hline 9. Prevention focus & 54.09 & 15.84 & $-.09 *$ & -.07 & $-.11 *$ & -.01 & -.07 & -.03 & $.22 * *$ & .07 & .50 & & & \\
\hline 10. Promotion focus & 69.37 & 16.74 & $.26^{* *}$ & $.24 * *$ & $.24 * *$ & $.13 * *$ & $.28 * *$ & $.21 * *$ & .08 & $.20 * *$ & $-.16^{* *}$ & .79 & & \\
\hline 11. Emotional exhaustion & 47.84 & 24.72 & $-.52 * *$ & $-.46^{* *}$ & $-.51 * *$ & $-.33 * *$ & $-.35 * *$ & $-.52 * *$ & -.01 & $-.43 * *$ & $.20 * *$ & $-.27 * *$ & .87 & \\
\hline 12. Depersonalization & 22.13 & 19.82 & $-.33 * *$ & $-.30 * *$ & $-.33 * *$ & $-.18 * *$ & $-.21 * *$ & $-.34 * *$ & -.04 & $-.24 * *$ & $.24 * *$ & $-.19 * *$ & $.58 * *$ & .72 \\
\hline
\end{tabular}


Figure 1. Means Values of Pre-crisis, Beginning of Crisis and High Crisis Samples

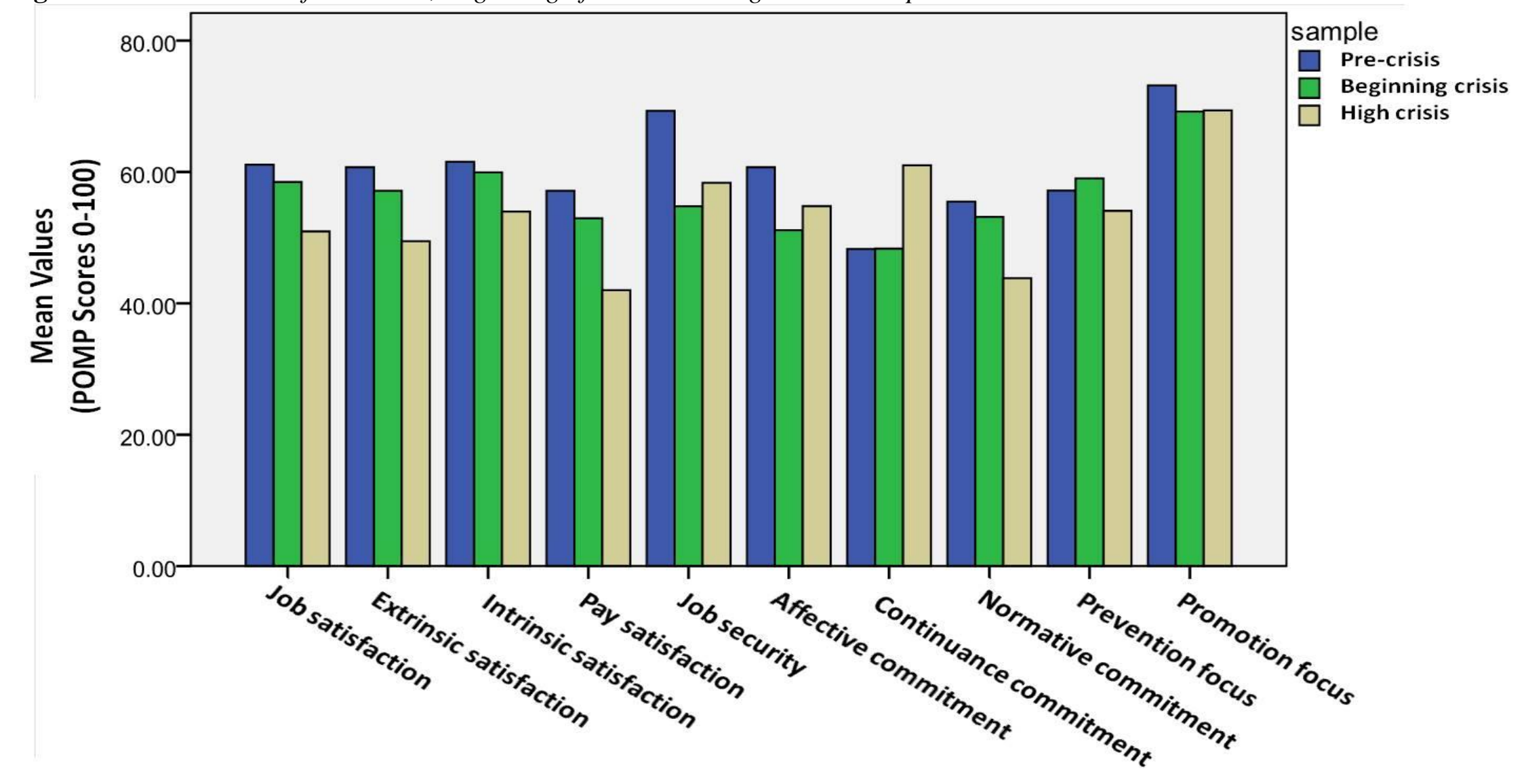


Table 2. Means, Standard Deviations and Difference Test Results Controlling for Age and Gender

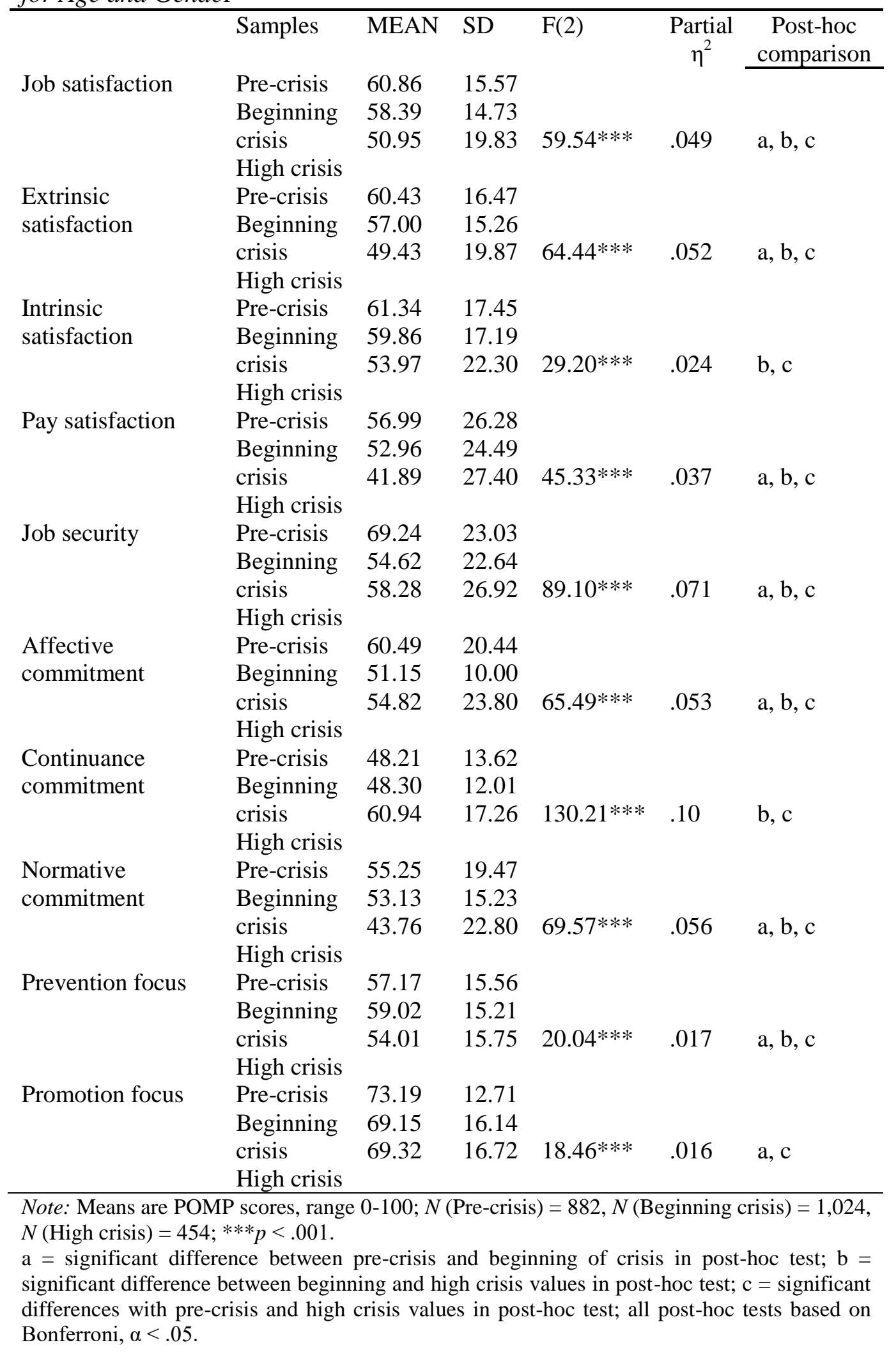


Hypothesis 2 predicted relations of job satisfaction and commitment with burnout. As can be seen in Table 1, this hypothesis is largely supported by the correlations. With the exception of continuance commitment which was neither related to emotional exhaustion nor to depersonalization, all other correlations, were significant and negative. This means that employees who reported less satisfaction and commitment were more likely to report higher levels of burnout.

Hypothesis 3 predicted that employees who were personally affected by the crisis by their own experiences of unemployment would report more negative attitudes than those less affected. We tested this hypothesis with ttests and results are presented in Table 3 and Figure 2. Results show that those participants with personal experiences of unemployment in the past (comprising almost $12 \%$ of the sample) are worse off on almost all variables compared to those without these experiences.

Table 3. Means, Standard Deviations and Difference between Individuals with (UE) and without Unemployment Experience (no-UE)

\begin{tabular}{|c|c|c|c|c|c|}
\hline & Samples & MEAN & SD & $\mathrm{t}$ & $\overline{\eta^{2}}$ \\
\hline \multirow[t]{2}{*}{ Job satisfaction } & No-UE & 51.90 & 19.11 & & \\
\hline & UE & 43.53 & 23.61 & $2.45^{*}$ & .018 \\
\hline \multirow[t]{2}{*}{ Extrinsic satisfaction } & No-UE & 50.78 & 19.05 & & \\
\hline & UE & 39.01 & 22.87 & $4.09 * *$ & .037 \\
\hline \multirow[t]{2}{*}{ Intrinsic satisfaction } & No-UE & 54.60 & 21.57 & & \\
\hline & UE & 48.65 & 26.97 & 1.53 & .007 \\
\hline \multirow[t]{2}{*}{ Pay satisfaction } & No-UE & 43.45 & 26.96 & & \\
\hline & UE & 30.93 & 28.80 & $3.13 * *$ & .022 \\
\hline \multirow[t]{2}{*}{ Job security } & No-UE & 61.38 & 24.75 & & \\
\hline & UE & 34.62 & 31.24 & $5.94 * *$ & .101 \\
\hline \multirow[t]{2}{*}{ Affective commitment } & No-UE & 56.35 & 23.04 & & \\
\hline & UE & 42.75 & 26.41 & $3.94 * *$ & .033 \\
\hline \multirow[t]{2}{*}{ Continuance commitment } & No-UE & 61.07 & 17.42 & & \\
\hline & UE & 60.83 & 16.34 & 0.09 & .000 \\
\hline \multirow[t]{2}{*}{ Normative commitment } & No-UE & 44.25 & 22.62 & & \\
\hline & UE & 40.49 & 24.50 & 1.12 & .003 \\
\hline \multirow[t]{2}{*}{ Prevention focus } & No-UE & 53.77 & 15.63 & & \\
\hline & UE & 56.54 & 17.60 & -1.18 & .003 \\
\hline \multirow[t]{2}{*}{ Promotion focus } & No-UE & 69.49 & 16.70 & & \\
\hline & UE & 68.80 & 17.04 & 0.28 & .000 \\
\hline \multirow[t]{2}{*}{ Emotional Exhaustion } & No-UE & 47.04 & 24.54 & & \\
\hline & UE & 54.49 & 25.69 & $-2.05^{*}$ & .010 \\
\hline \multirow[t]{2}{*}{ Depersonalization } & No-UE & 21.44 & 19.76 & & \\
\hline & UE & 26.93 & 19.82 & -1.88 & .008 \\
\hline
\end{tabular}

Note: Means are POMP scores, range 0-100, UE = unemployment experience, no-UE = no unemployment experience; $N($ no UE $)=401, N(\mathrm{UE})=53, * p<.05, * * p<.01$. 
Figure 2. Means Values of Individuals with and without Unemployment Experience (high crisis sample)

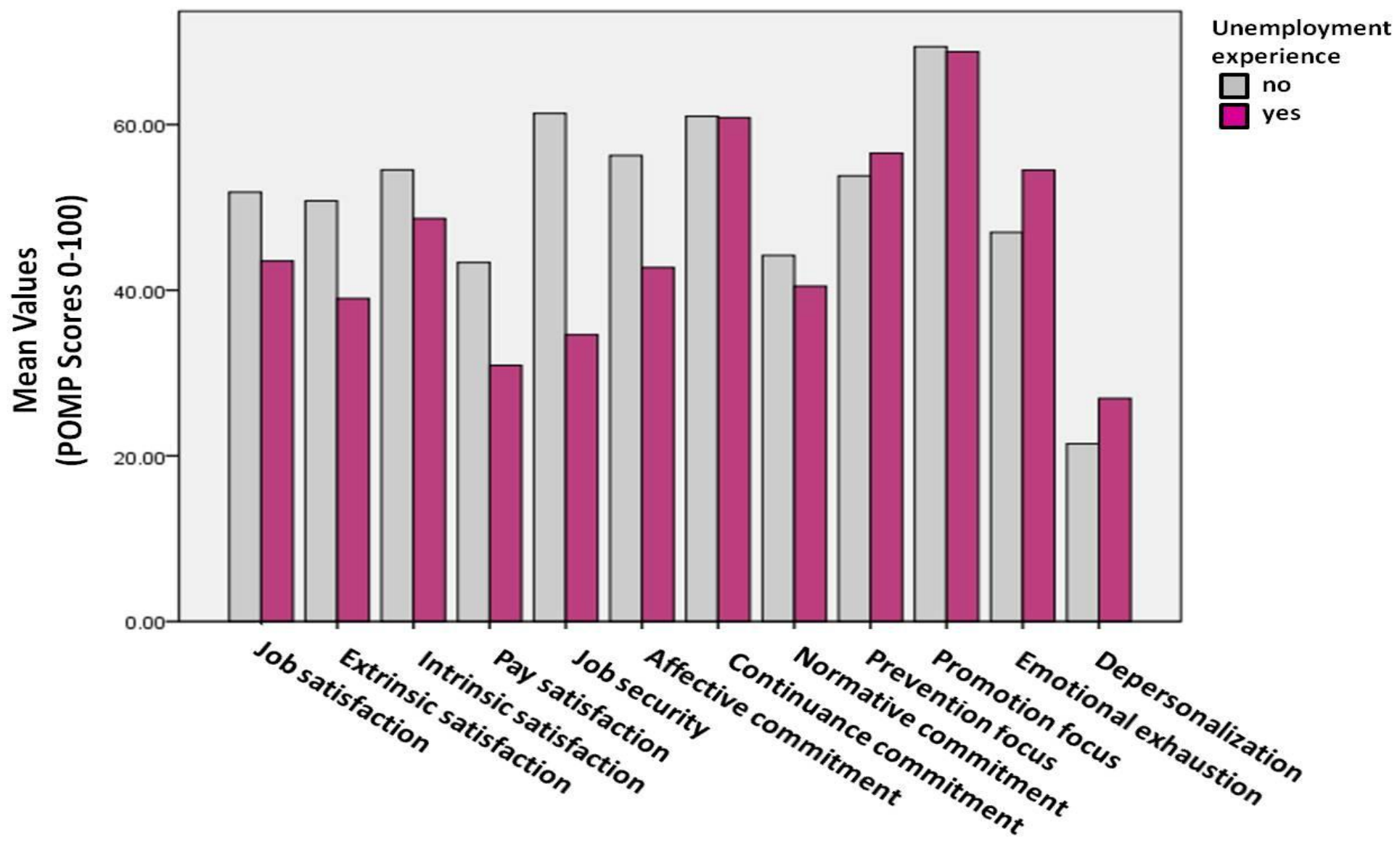




\section{Discussion}

This study followed up on Markovits and colleagues' (2014) findings and aimed at investigating whether Greek employees have restored their job attitudes and commitment or whether they are still suffering from the economic crisis over half a decade after its onset. Furthermore, we extended the focus to well-being and experienced unemployment. We investigated the relationship of job attitudes and commitment with burnout and whether experienced unemployment is related to reduced job attitudes, commitment and well-being.

Our findings clearly show that the ongoing crisis has further detrimental effects on employees' job attitudes and their normative commitment. Almost all dimensions of job satisfaction were lower compared to both the data before and at the beginning of the crisis. This means that Greek employees intrinsic and extrinsic motivation suffers from the ongoing crisis and it shows that people find it very difficult to adapt to such a situation. The only exception is job security. While it remains still much lower than before the crisis, it has recovered since 2010 - probably because employees who were not unemployed ( $85 \%$ of the sample) after six years of the crisis felt more certain that they would also keep their jobs in the future. Overall, though, employees did not "get used" to the adverse conditions created by the economic crisis, instead the continuing crisis leads to further reductions in job attitudes.

We found quite different trajectories for the three commitment aspects. Normative commitment was substantially reduced in comparison to both previous time points. Affective commitment went slightly up compared to the beginning of the crisis but remained significantly lower than before the crisis. Hence, the crisis holds its negative impact on affective and moral engagement with the organizations. Interestingly, continuance commitment was drastically increased in comparison to both previous time points. It seems that it requires an extended time period for an economic crisis to unravel its effects on employees' continuance commitment that helps employees to safeguard their current jobs by all means.

Employees' promotion focus, that relates to positively approaching new challenges and focusing on aspirations (Higgins 1997), remained as low as at the beginning of the crisis. However, employees' prevention focus, related to security orientation and risk aversion (Higgins 1997), also went down compared to both previous time points. Hence, the economic crisis not only reduces employees' self-regulation with respect to an orientation toward accomplishments and aspirations, but also with regard to their focus on maintaining safety and preventing further losses, because the crisis seems to have taken opportunities to attain goals and it generated long-term uncertainty that prevents any prospects of job-related security.

Unemployment represents one of the major traumatic events in people's lives (Dooley et al. 1996, Murphy and Athanasou 1999, Paul and Moser 2006) and many Greek employees were affected by unemployment. The current analysis showed that individuals, who are currently employed but who experienced unemployment in the past, reported reduced job attitudes. 
Particularly their satisfaction with job security was obviously most severely affected, compared to employees who were never personally affected by unemployment. Furthermore, their affective engagement and bonds to their current organizations as well as their well-being have suffered from previous unemployment experiences. Emotional exhaustion is the main dimension of burnout and captures employees' general well-being at work. One may naively argue that unemployed individuals should be well rested and should hence not experience work-related stress that reduces their well-being. However, the omnipresence of job insecurity during the crisis puts an existential threat on people's well-being at work, which is severely enhanced for individuals who have experienced the impact of this threat in person.

Hence, unemployment does not only affect individuals during the unemployed phase, but long-term detrimental effects seem to mitigate people's well-being even after the successful end of the unemployment. This finding puts a new and concerning perspective on the long-term effects of unemployment during an economic crisis on well-being, which seems to require a long-term recovery beyond the mere overcoming of unemployment by a new assignment.

Finally, we investigated the relationships between job attitudes, commitment, and burnout. We found detrimental effects of the crisis on wellbeing in general due to its effects on job attitudes and commitment and of unemployment experiences. The economic crisis negatively affects employees' attitudes and the lower attitudes in turn translate into lower well-being, i.e. emotional exhaustion and depersonalization. The results of all three "waves" of our survey vividly show that people, by and large, have difficulties to cope with economic crises, since the crisis influences their everyday lives and their standard and quality of living. Moreover, the detrimental effects on job attitudes and commitment question traditional organizational and work "bondages" and in effect internalize problems and difficulties.

In other words, the monetary effects of an economic crisis are as important as the human and behavioral ones. Unfortunately, austerity measures focus on the former ones, and pay little attention on the latter. This study shows that people's attitudes and behaviors have, by and large, get worse as a result of the continuation of the crisis and the imposition of austerity measures and "Memorandum" programs, and this development has serious and negative implications to people's expectations for the future.

\section{Limitations}

One limitation of the current study is the between-subjects design. We present a comparison of different samples collected over time and we did not investigate changes within the same individuals. This design comes with the possible limitations of random sampling error that may distort the findings. However, the sampling procedure aimed at collecting comparable and relatively large representative samples within one region of Greece. We therefore have some confidence in the validity of findings. However, we were 
not able to test whether participants' household income or other objective differences would largely influence their attitudes. We expect that this could be the case and future research may aim at gathering much larger and ideally representative samples to account for such variables as controls and/or moderators.

Secondly, we need to critically evaluate our cross-sectional design and its general limitations. Common-method variance is one major concern in crosssectional field data using Likert-type response formats. However, looking at the correlation tables of both data sets, we can see correlations ranging from zero to strong effects. This variability in associations indicates a theoretically meaningful differentiation in effect sizes with, for instance, sub-dimensions of one domain are strongly correlated, while outcomes of different domains are less strongly correlated. Based on this observation we believe that commonmethod variance is not largely affecting our results.

A third limitation relates to the use of self-report questionnaires. It is difficult to envisage a way in which individual attitudes can be assessed other than through self-report.

Finally, our research approach was quantitative and while we do see that some of the job attitudes remain negative or become even worse over the prolonged crisis, we do not know what it means to the people involved and how they individually cope with the crisis. People have capabilities (Sen 1985) that allow them to different degrees to restore their freedom to act in times of adversity. Future research may use this as a starting point for a more qualitative and in-depth analysis of why some people respond more negatively to the adverse conditions than others.

\section{Conclusion}

Employees in Greece suffer prolonged detrimental effects from the economic crisis. Their well-being, job attitudes and self-regulation are all affected by this crisis. The continuation of austerity measures and the persistence of economic and social policies that reduce wages, harm low income-earners and seriously affect employment conditions and prospects will only add to a downturn spiral effect: crisis causes poverty, poverty adds to crisis, and so on. This study shows that Greek employees would benefit from future-oriented policies that promise an optimistic outlook and a regain of positive job and life developments. An alternative socio-economic "blend" should be adopted that moves away from restrictive monetary-oriented policies to more people-oriented ones. As long as future aspirations remain stagnated and attitudes suffer as a result of crisis' continuation, a U-turn of these developments cannot be expected. 


\section{References}

Acker GM (1999) The impact of clients' mental illness on social workers' job satisfaction and burnout. Health Social Work 24(2): 112-119.

Allen NJ, Meyer JP (1990) The measurement and antecedents of affective, continuance and normative commitment to the organization. Journal of Occupational Psychology 63(1): 1-18.

Dooley D, Fielding J, Levi L (1996) Health and unemployment. Annual Review of Public Health 17: 449-465.

Eagly A, Chaiken S (1995) Attitude strength, attitude structure and resistance to change. In R. Petty and J Kosnik (Edn.) Attitude Strength, pp. 413-432.

Evans S, Huxley P, Gately C, Webber M, Mears A, Pajak S, Medina J, Kendall T, Katona C (2006) Mental health, burnout and job satisfaction among mental health social workers in England and Wales. British Journal of Psychiatry 188(1): 7580.

Herscovitch L, Meyer JP (2002) Commitment to organizational change: Extension of a three-component model. Journal of Applied Psychology 87(3): 474-487.

Higgins ET (1997) Beyond pleasure and pain. American Psychologist 52(12): 12801300.

King RC, Sethi V (1997) The moderating effect of organizational commitment on burnout in information systems professionals. European Journal of Information Systems 6(2): 86-96.

Leiter MP, Maslach C (1988) The impact of interpersonal environment on burnout and organizational commitment. Journal of Organizational Behavior 9(4): 297-308.

Lockwood P, Jordan CH, Kunda Z (2002) Motivation by positive or negative role models: Regulatory focus determines who will best inspire us. Journal of Personality and Social Psychology 83(4): 854-864.

Loewenstein G (2007) Affect regulation and affective forecasting. In Gross JJ (Ed.) Handbook of Emotion Regulation, pp. 180-203.

Markovits Y, Boer D, Van Dick R (2014) Economic crisis and the employee: The effects of economic crisis on employee job satisfaction, commitment, and selfregulation. European Management Journal 32(3): 413-422.

Markovits Y, Davis AJ, Fay D, Van Dick R (2010) The link between job satisfaction and organizational commitment - Differences between public and private sector employees. International Public Management Journal 13(2): 177-196.

Markovits Y, Davis AJ, Van Dick R (2007) Organizational commitment profiles and job satisfaction among Greek private and public sector employees. International Journal of Cross-Cultural Management 7(1): 77-99.

Markovits Y, Ullrich J, Van Dick R, Davis AJ (2008) Regulatory foci and organizational commitment. Journal of Vocational Behavior 73(3): 485-489.

Martin U, Schinke SP (1998) Organizational and individual factors influencing job satisfaction and burnout of mental health workers. Social Work in Health Care 28(2): 51-62.

Maslach C, Jackson SE (1981) The measurement of experienced burnout. Journal of Occupational Behavior 2(2): 99-113.

McGuire W, Lindzey G, Aronson E (1985) Attitudes and attitude change. Handbook of social psychology: Special fields and applications Vol. 2, pp. 233-346.

Meyer JP, Stanley DJ, Herscovitch L, Topolnytsky L (2002) Affective, continuance, and normative commitment to the organization: A meta-analysis of antecedents, correlates, and consequences. Journal of Vocational Behavior 61(1): 20-52. 
Murphy GC, Athanasou JA (1999) The effect of unemployment on mental health. Journal of Occupational and Organizational Psychology 72(1): 83-99.

Onyett S, Pillinger T, Muijen M (1997) Job satisfaction and burnout among members of community mental health teams. Journal of Mental Health 6(1): 55-66.

Paul KI, Moser K (2006) Incongruence as an explanation for the negative mental health effects of unemployment: Meta-analytic evidence. Journal of Occupational and Organizational Psychology 79(4): 595-621.

Penn M, Romano JL, Foat D (1988) The relationship between job satisfaction and burnout: A study of human service professionals. Administration in Mental Health 15(3): 157-165.

Rosales RA, Labrague LJ, Rosales GL (2013) Nurses' job satisfaction and burnout: Is there a connection? International Journal of Advanced Nursing Studies 2(1): 110.

Sen A (1985) Commodities and capabilities. Amsterdam, New York, N.Y.: Elsevier

Tsigilis N, Zacharopoulou E, Grammatikopoulos V (2006) Job satisfaction and burnout among Greek early educators: A comparison between public and private sector employees. Educational Research and Review 1(8): 256-261.

Weiss DJ, Dawis RV, England GW, Lofquist LH (1967). Manual for the Minnesota Satisfaction Questionnaire. Minnesota Studies in Vocational Rehabilitation Bulletin 22.

Xanthopoulou D, Epitropaki O (2015) Occupational health psychology in Greece: Luxury or necessity? The Occupational Health Psychologist 12(1): 3-5. 
